\title{
THE INFLUENCE OF MEDIUM CREDIBILITY TOWARDS INFORMATION ADOPTION IN INDONESIA STOCK INVESTMENT VIRTUAL COMMUNITIES
}

\author{
Hardyin Alexander Hutapea, Achmad Nizar Hidayanto, Fatimah Azzahro \\ and Widijanto Satyo Nugroho \\ Faculty of Computer Science, Universitas Indonesia \\ Kampus UI Depok, Indonesia
}

\begin{abstract}
This study aims to analyze the influence of medium credibility towards information adoption through information credibility and perceived usefulness. The context of this study is virtual communities dedicated to stock investment. Based on the survey obtained from 333 respondents, our analyses show that medium credibility positively influences information credibility and perceived usefulness. Meanwhile, information credibility and perceived usefulness are the antecedents of information adoption. Additionally, information credibility positively influences perceived usefulness. In particular, it can be concluded that in the context of stock investment virtual communities, medium credibility can influence information adoption through information credibility and perceived usefulness. The theoretical and practical implications of this study, and its limitations are also discussed.
\end{abstract}

\section{KEYWORDS}

Information Adoption, Information Credibility, Medium Credibility, Perceived Usefulness, Stock Investment Virtual Communities

\section{INTRODUCTION}

The capital market can drive macroeconomic turnover in a country and has potential to improve one's living standards (OECD, 2018). However, in Indonesia, the capital market is the least utilized financial sector due to low capital market literacy (Otoritas Jasa Keuangan, 2016). The index of capital market literacy in Indonesia is only $4.4 \%$. In other words, among 1000 people, only 44 people have sufficient knowledge on capital market. In order to improve the literacy index, the Financial Services Authority (OJK) launched the National Strategy for Financial Literacy in 2017. One of its initiatives is to encourage the use of information technology-based media in financial education. As the number of internet users in Indonesia continually increasing, the internet-based media such as virtual communities is expected to be the most efficient way to improve the index of capital market literacy in Indonesia (We are social, 2018).

Virtual communities are online social networks where people with the same interests, goals or activities interact to share information and knowledge (Chiu, Hsu and Wang, 2006). In Indonesia, the popularity of virtual communities is increasing along with the rapid development of social media and instant messaging users. The convenience provided by virtual community to share and search information is among the reasons that motivate people to join virtual community. This also applies to stock investors that continuously need to find the most updated information to improve their portfolio performance. As social media and instant messaging become the two of the most widely used applications by internet users in Indonesia, stock investment virtual communities are often formed through social media (i.e. Facebook and Instagram), as well as instant messaging applications (e.g. WhatsApp and Telegram group). Additionally, there is also a social media that specifically serve stock investors, Stockbit.

Virtual community is often used by investors to exchange information about capital markets. In the capital market, investors who are able to get credible information earlier may secure greater profits. Thus, stock investors experience the fear of missing out (FOMO) and consider information as important commodities. The 
urgency of information has encouraged stock investors to search for up-to-the-minute information, including through virtual communities. However, despite its ability to spread information quickly, not all virtual communities circulating trustworthy information. In a study conducted by Bates and Annette, $85 \%$ of journalists stated that, in general, the information available on social media was less credible than conventional media due to lack of validation, verification and reporting standards (Bates and Annette, 2009).

Numerous studies have documented that medium credibility is the antecedent of information credibility (Kang, 2010; Westerman, Spence and Van Der Heide, 2012). Audience tends to assess the credibility of a medium before assessing the credibility of information distributed through it. On the other hand, several studies have documented the positive effects of information credibility on information adoption (Wathen and Burkell, 2002; Bates and Annette, 2009). However, there have not been many studies that discuss whether medium credibility can influence information adoption. To fill the gap, this study tries to evaluate whether medium credibility can also influence users' decision to adopt information through information credibility and information usefulness.

The rest of the paper is organized as follow. In the following section, we review the relevant literature on medium credibility, information credibility, and information adoption. Additionally, our proposed model and hypotheses development are also presented in the literature review section. We then describe our methodology and present our results, ending with a discussion and conclusion of our findings, including our theoretical implication, practical implications, and research limitations.

\section{LITERATURE REVIEW AND HYPOTHESES DEVELOPMENT}

\subsection{Medium Credibility as Antecedent of Information Credibility and Perceived Usefulness}

According to Metzger et al., (2003), medium credibility defines users' perceived level of trust towards a specific media. Medium credibility focus on the channel through which content is delivered rather than the content itself. To measure medium credibility, prior research used medium interfaces and features, which only represent the technical ability of medium to deliver information. However, the past approach is unable to represent users' phycological factors in evaluating medium credibility. Therefore, this study adopted the medium credibility theory developed by $\mathrm{Li}$ and Suh that combined both the technical and psychological aspects of users in assessing media credibility (Li and Suh, 2015).

Based on Li and Suh theory, medium credibility is defined as a second-order construct that consists of medium dependency (psychological aspects), interactivity, and medium transparency (technical aspect). First, medium dependency is defined as the extent to which users rely on a particular virtual community to find information about stock investment (Ito et al., 2008). Meanwhile, interactivity is defined as media ability to increase user involvement. This includes the media interface, features, and its ease of use that help users to connect with each other ( $\mathrm{Li}$ and Suh, 2015). Lastly, medium transparency refers to the ability of media to support the exchange of information between individuals candidly (Yang and Lim, 2009). According to Yang and Lim, medium transparency is the key to building relational trust. For example, blogs are considered more credible than conventional media because it provides more independent and transparent information (Andrews, 2003).

In the context of stock investment virtual communities, each virtual community has its own characteristics which lead to different credibility assessment from its users. Previous research found that medium credibility influences information credibility (Westerman, Spence and Van Der Heide, 2012; Li and Suh, 2015). Although people tend to have dependency to get information from their favorite media, they do not always feel that their most preferred media was the most credible. This also the case for stock investors which rely heavily on information to make decision. Hence, before deciding whether information from a specific virtual community is credible, one often assess the credibility of medium beforehand. If the virtual community does not provide good interactivity and transparency, then, users may find themselves to distrust the provided information. Based on these explanations, the authors draw the hypothesis:

H1: Medium credibility has a positive effect on information credibility.

Several researchers found that medium credibility also influences information credibility (Li and Suh, 2015; Hajli, 2018; Madli et al., 2018). Media with high interactivity may provide rich and relevant information for 
users. In the context of stock investment virtual community, if the virtual community provides features and interface that encourage their users to interact and share information, it will build up the relevant content for its users. Hence, when users consider a virtual community as a credible media, for example having good interactivity and transparency, they will likely believe that the information provided by the media is useful for them. Based on this, it was concluded that:

$\mathrm{H} 2$ : The credibility medium has a positive effect on perceived usefulness.

\subsection{Information Credibility as Antecedent of Perceived Usefulness and Information Adoption}

Information credibility is defined as the extent to which information can be trusted by the recipient, thus can influence the recipient to take certain actions (McKnight and Kacmar, 2007). Meanwhile, information adoption is defined as a process of involvement to use information that is intentionally carried out by information recipients (Yan et al., 2016). In virtual community, adopting behavior is often performed (Cheung, Lee, and Rabjohn, 2008). For example, buyers in e-commerce platform often look for reviews from other users and ask questions to others before making purchases (Sussman and Siegal, 2003; Pitta and Fowler, 2005). This also happens in the context of stock investment virtual community. The member of stock investment virtual community often evaluates the credibility of information before deciding whether they will adopt the information. The process of adopting information itself starts when user agreeing to the information, following the suggestion, and/or making decisions based on that information (Sussman and Siegal, 2003). Several previous studies found that information credibility significantly influences information adoption (McKnight and Kacmar, 2007; Cheung et al., 2009; Yan et al., 2016). Therefore, the authors propose the following hypothesis:

H3: Information credibility has a positive effect on information adoption.

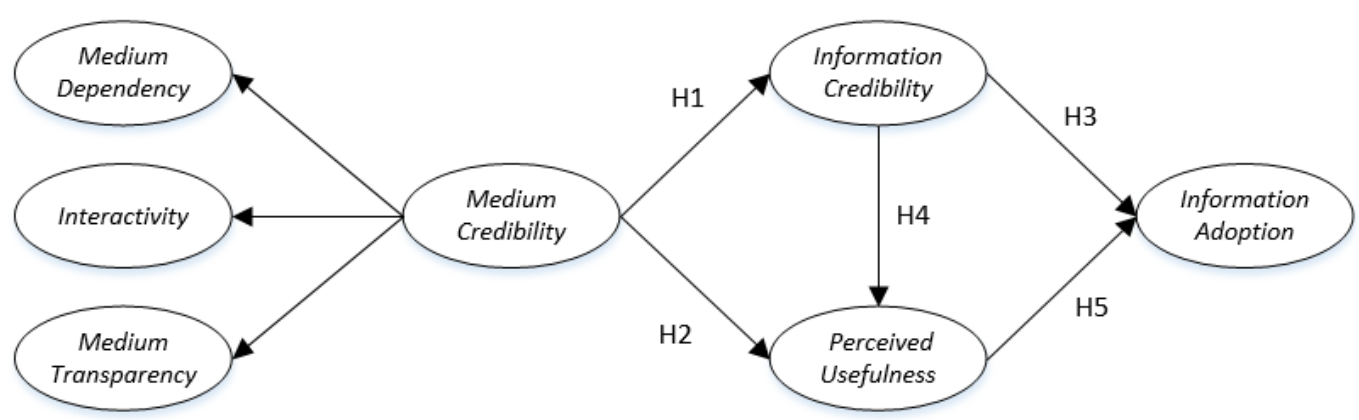

Figure 1. Research Model

In this era of data, there is abundance of information available every day. However, not all information is trustworthy and useful. Although information credibility can influence information adoption, only useful and relevant information will be adopted by people. On the contrary, useful information can predict users' intention in adopting information. However, untrustworthy information will reduce the usefulness or even increase the risk of information, especially in the context of stock investment which has direct impact on one's finances. Therefore, information credibility is a very important factor to determine whether information is useful or not. The argument is supported by several previous studies which showed a positive relationship between information credibility and perceived usefulness (Ko et al., 2005; McKnight and Kacmar, 2007; Hajli, 2018). Therefore, the authors propose the following hypothesis:

$\mathrm{H} 4$ : Information credibility has a positive effect on perceived usefulness.

According to Hussain et al, information adoption behavior is essential for consumers before making a decision regarding the quality of a product or service, especially in an online environment (Hussain et al., 2018). Thus, information usefulness is considered to be essential to predict whether further adoption of information will happen. In the context of stock investment, information is considered useful when it can help 
improve one's performance in stock investing. When someone considers information useful to them, they will tend to adopt that information to benefit from it (Erkan and Evans, 2016; Hussain et al., 2018). Therefore, the authors propose the following hypothesis:

H5: Perceived usefulness has a positive effect on information adoption.

\section{METHODOLOGY}

We tested the proposed hypotheses (Figure 1) using an online survey distributed to stock investors that also members of stock investment virtual communities. The questionnaire contains four measures addressing the research questions. First, medium credibility and information credibility construct are adopted from Li and Suh (2015). Next, perceived usefulness construct is adapted from (Tseng and Wang, 2016). Lastly, information adoption construct is adopted from Sussman and Siegal (2003). Responses to all the item measures were captured using six-point Likert-type scales. We avoid using odd number Likert scale due to respondents' tendency to choose the median or neutral statement. Since the research is conducted in Indonesia, each item on the questionnaire is translated from English to Bahasa Indonesia to facilitate respondents' understanding.

We received completed responses from 406 stock investors that are members of at least one stock investment virtual community. The virtual communities are mostly based on instant messaging or social media, with WhatsApp, is the most popular platform. After deleting unmatched and/or missing cases, the final sample consisted of 333 matched questionnaires. Table 1 summarizes the demographic data of our respondents. According to F. Hair Jr et al. (2014), the ideal sample size should be at least ten times the number of indicators. Since this study are measured by using 22 indicators, the minimum sample is reached.

Table 1. Demography of Respondents

\begin{tabular}{llrr}
\hline Variable & \multicolumn{1}{c}{ Items } & Frequency & Percentage \\
\hline Sex & Male & 260 & $78,08 \%$ \\
\cline { 2 - 4 } & Female & 73 & $21,92 \%$ \\
\hline Age & $<20$ & 67 & $20.12 \%$ \\
\cline { 2 - 4 } & $21-25$ & 144 & $43,24 \%$ \\
\cline { 2 - 4 } & $26-30$ & 49 & $14,71 \%$ \\
\cline { 2 - 4 } & $31-35$ & 28 & $8,41 \%$ \\
\cline { 2 - 4 } & $35-40$ & 21 & $6,31 \%$ \\
\hline Income & IDR1 million & 75 & $22,52 \%$ \\
(in IDR per month) & IDR1-5 million & 103 & $30.93 \%$ \\
& IDR5 - 10 million & 84 & $25,23 \%$ \\
& $>10$ million & 71 & $21,32 \%$ \\
Duration of becoming a & 1-2 year & 168 & $50.45 \%$ \\
member of stock investment & 96 & $28,83 \%$ \\
virtual community & $2-3$ year & 38 & $11,41 \%$ \\
& $4-5$ year & 12 & $3,60 \%$ \\
& $>5$ year & 19 & $5,71 \%$ \\
\hline
\end{tabular}

\section{RESEARCH RESULTS}

\subsection{Measurement Model Evaluation}

The measurement model was assessed to ensure the appropriate use of instruments, including its convergent validity, discriminant validity, and reliability. To assess the reliability of construct, the authors ensure that the composite reliability values are greater than 0.70 as suggested by Robinson et al (1991). Table 2 summarizes the loading ranges, AVE, and composite reliability for all items. Meanwhile, to ensure construct validity, all measures were adapted from existing validated scales whenever possible. Additionally, the convergent validity is measured by using loading factors and AVE. While the loading factors must be greater than 0.60 . the AVE value must be greater than 0.50 . Lastly, Table 3 shows that the square root of the AVE for each construct is higher than correlations between constructs, suggesting that the measurement model have good discriminant validity. 
Table 2. The Results of Reliability and Validity Testing for the Constructs.

\begin{tabular}{lccccccccc}
\hline Factors & Items & $\begin{array}{c}\text { Loading } \\
\text { Factor }\end{array}$ & AVE & CR & Factors & Items & $\begin{array}{c}\text { Loading } \\
\text { Factor }\end{array}$ & AVE & CR \\
\hline MT & MT1 & 0.68 & & & & I1 & 0.75 & & \\
& MT2 & 0.641 & 0.501 & 0.716 & INT & I2 & 0.855 & 0.610 & 0.861 \\
& MT3 & 0.706 & & & & I3 & 0.821 & & \\
IC & IC1 & 0.874 & & & MD & MD1 & 0.686 & & \\
& IC2 & 0.862 & & & & MD2 & 0.691 & & \\
& IC3 & 0.895 & \multirow{2}{*}{0.704} & 0.877 & & MD3 & 0.729 & 0.507 & 0.860 \\
PU & PU1 & 0.86 & & & & MD4 & 0.685 & & \\
& PU2 & 0.804 & & & & MD5 & 0.654 & & \\
& PU3 & 0.852 & & & & MD6 & 0.75 & & \\
IA & IA1 & 0.795 & \multirow{2}{*}{0.673} & 0.861 & & & & & \\
& IA2 & 0.808 & & & & & & &
\end{tabular}

MT: Medium Transparency, IC: Information Credibility, PU: Perceived Usefulness,

IA: Information Adoption, INT: Interactivity, MD: Medium Dependency, MC: Medium Credibility

Table 3. Correlations between constructs

\begin{tabular}{ccccc}
\hline & IA & PU & IC & MC \\
\hline IA & $\mathbf{0 . 8 2 0}$ & & & \\
PU & 0.763 & $\mathbf{0 . 8 3 9}$ & & \\
IC & 0.743 & 0.782 & $\mathbf{0 . 8 7 7}$ & \\
MC & 0.666 & 0.664 & 0.671 & $\mathbf{0 . 8 5 6}$ \\
\hline
\end{tabular}

\subsection{Structural Model Evaluation}

For all hypotheses, we then conducted an evaluation on the structural model using AMOS 24. All proposed hypotheses were fully supported with significance level $p=0.05$ (Table 4 ). Medium credibility is proved to be the antecedent of both information credibility and perceived usefulness ( $p$-value for $\mathrm{H} 1 \& \mathrm{H} 2$ are less than $0.05)$. Next, information credibility significantly influences perceived usefulness ( $p$-value of $\mathrm{H} 3<0.05$ ). Lastly, H4 and H5 show that both predictors appeared to significantly predict information adoption: information credibility ( $p 0.017)$ and perceived usefulness ( $p 0.003$ ). Additionally, the $\mathrm{R}^{2}$ value was used to assess the coefficient of determination. $\mathrm{R}^{2}$ for information adoption, perceived usefulness, and information credibility are, respectively, $0.661,0.649$, and $0.473 . \mathrm{R}^{2}$ value for information adoption from stock investment virtual communities is 0.473 suggesting that $47.3 \%$ of the variance in information adoption of stock investment virtual communities can be explained by factors in the research model.

Table 4. Hypothesis Testing Result

\begin{tabular}{llrrc}
\hline Hypothesis & \multicolumn{1}{c}{ Path } & Estimate & $\boldsymbol{p}$ & Results \\
\hline H1 & Medium Credibility $\rightarrow$ Information Credibility & 0.688 & 0.007 & Accepted \\
H2 & Medium Credibility $\rightarrow$ Perceived Usefulness & 0.275 & 0.005 & Accepted \\
H3 & Information Credibility $\rightarrow$ Perceived Usefulness & 0.591 & 0.004 & Accepted \\
H4 & Information Credibility $\rightarrow$ Information Adoption & 0.298 & 0.017 & Accepted \\
H5 & Perceived Usefulness $\rightarrow$ Information Adoption & 0.559 & 0.003 & Accepted
\end{tabular}




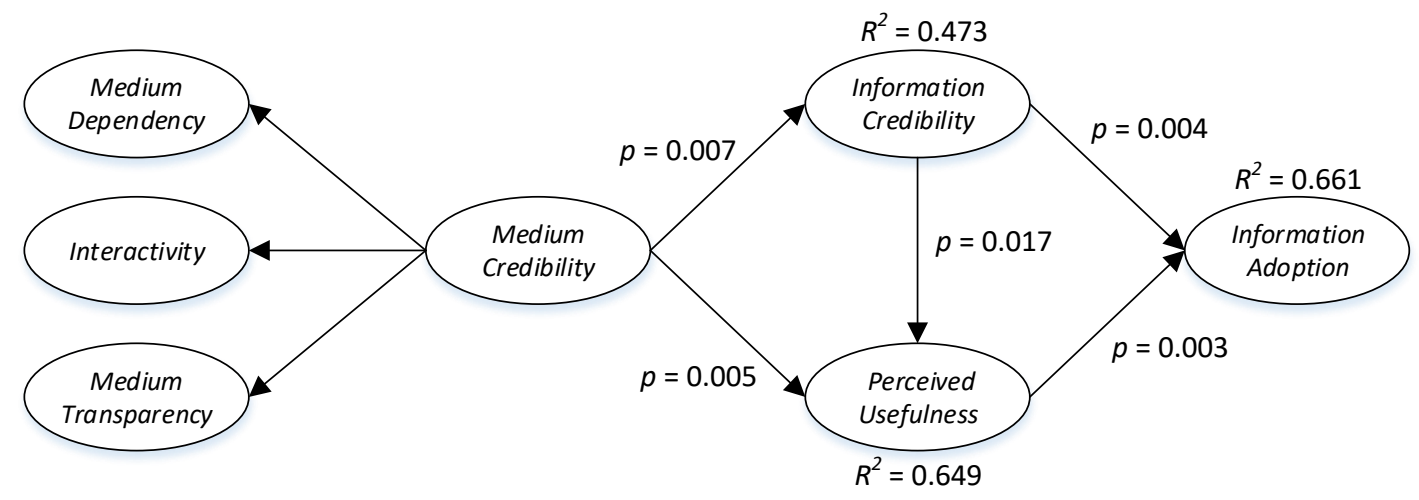

Figure 2. Research Result

\section{DISCUSSION AND IMPLICATIONS}

In light of the approval of H1 (medium credibility influence information credibility), we extended existing findings from Li and Suh (2015). Additionally, our result establishes an expansion of the existing findings from Eysenbach, (2008) in the now context of stock investment virtual communities. Our study also found that information credibility influences perceived usefulness. This finding also strengthens the findings of mobile word-of-mouth study by Erkan and Evans, (2016) and adopting information in food products purchase by Hussain et al. (2018). Through this research, the author further strengthens the theory of information credibility with information usefulness, as discussed by Hajli, (2018) and Ko et al., (2005). This study also found that users of stock investment virtual communities tend to adopt credible information. The process of adopting information in this study is characterized by users agreeing to information, then users follow the suggestions contained in information, and users are encouraged to make decisions based on information. Therefore, it can be concluded that before adopting stock information the user usually considers the information credible. This finding supports the research of Cheung et al., (2009) which concluded that the credibility of information affects the adoption of information. Finally, perceived usefulness also affects information adoption. Users will tend to adopt stock information if they feel the information is useful to them. In addition to assessing its credibility, the user also assesses whether information is useful to him before he adopts the information.

This study offers both theoretical and practical implication. First, through this research, the author proves that the medium credibility influences information adoption through perceived usefulness and information credibility. Several previous studies have indeed discussed the relationship of medium credibility with information credibility as well as the relationship between information credibility and information adoption (Cheung et al., 2009; Li and Suh, 2015). However, not many studies have discussed how the credibility of a communication medium influences the adoption of information by its users.

Based on the results of the analysis, the authors found that the credibility medium has a direct correlation with perceived usefulness. Several previous studies that discussed the usefulness of information in virtual communities usually linked it to information credibility and the quality of arguments (Huang and Kuo, 2014; Erkan and Evans, 2016; Hussain et al., 2018). Therefore, the results of this study are expected to provide a new perspective on the relationship between the credibility and perceived usefulness medium. This study also confirms the dimensions of the medium credibility outlined by Li and Suh (2005). Previous research on the credibility medium generally discussed the medium credibility attribute based on the features or design of a communication medium and not many focused on discussing medium credibility from the user's point of view.

On the practical level, our findings suggest that stock investors can assess the medium credibility, or in this context, the credibility of virtual communities to improve the possibility of getting credible and useful information. One can evaluate the interactivity of medium, along with the medium dependency and medium transparency. Additionally, as this study shows that interactivity is part of medium credibility, social media that focus on stock investment such as Stockbit can improve their interactivity to ensure achieving better information credibility. By providing features that encourage users to interact with each other, the information credibility and perceived usefulness will improve. Thus, increasing the information adoption in investors. 


\section{CONCLUSION}

This paper concludes that; medium credibility influences information credibility and perceived usefulness. This indicates that the more credible a virtual community is, the information distributed in the virtual community will be perceived as more useful and credible by users. Additionally, this study also found that medium credibility has more influence towards information credibility than perceived usefulness. Meanwhile, information credibility affects perceived usefulness with a level of correlation that can be categorized as strong. Thus, it can be concluded that credible information will be considered more useful for users of stock investment virtual communities. Lastly, information credibility and perceived usefulness influence information adoption behavior, with perceived usefulness having a more significant influence compare to information credibility. Thus, it can be concluded that in adopting information in stock investment virtual communities, users are more concerned with the use of information than the credibility of the information.

This study also has several limitations. Firstly, the number of respondents who filled out this questionnaire were 330 respondents. Meanwhile, the number of stock investors in the Indonesian capital market has reached around 851,662 as of December 2018 (KSEI, 2018). Thus, the number of samples that are relatively small compared to the total population may not reflect the behavior of all stock investors in Indonesia. Additionally, the author suggests for future study to compare several social media or instant messaging applications that have different characteristics while using medium credibility theory.

\section{ACKNOWLEDGMENT}

We would like to thank Direktorat Riset \& Pengabdian Masyarakat for their support through Grant PIT9 (Grant No. NKB-0005/UN2.R3.1/HKP.05.00/2019).

\section{REFERENCES}

Andrews, P, 2003. Is Blogging Journalism? Available at: https://niemanreports.org/articles/is-blogging-journalism/ (Accessed: 2 April 2019).

Bates, D. and Annette, A, 2009. How the press uses and values public relations and other media resources and journalists. Washington, DC. Available at: www.cision.com (Accessed: 2 April 2019).

Cheung, C. M. K., Lee, M. K. O. and Rabjohn, N, 2008. The impact of electronic word-of-mouth: The adoption of online opinions in online customer communities. Internet Research, Vol. 18, No. 3, pp 229-247. doi: 10.1108/10662240810883290.

Cheung, M. Y. et al, 2009. Credibility of Electronic Word-of-Mouth: Informational and Normative Determinants of On-line Consumer Recommendations. International Journal of Electronic Commerce, Vol. 13, No. 4, pp 9-38. doi: 10.2753/JEC1086-4415130402.

Chiu, C. M., Hsu, M. H. and Wang, E. T. G, 2006. Understanding knowledge sharing in virtual communities: An integration of social capital and social cognitive theories. Decision Support Systems, Vol. 42, No. 3, pp 1872-1888. doi: 10.1016/j.dss.2006.04.001.

Erkan, I. and Evans, C, 2016. The influence of eWOM in social media on consumers purchase intentions: An extended approach to information adoption. Computers in Human Behavior, Vol. 61, pp 47-55. doi: 10.1016/j.chb.2016.03.003.

Eysenbach, G, 2008. Credibility of Health Information and Digital Media: New Perspectives and Implications for Youth, in Digital Media, Youth, and Credibility. pp 123-154. doi: 10.1162/dmal.9780262562324.123.

F. Hair Jr, J. et al, 2014. Partial least squares structural equation modeling (PLS-SEM). European Business Review, Vol. 26, No. 2, pp 106-121. doi: 10.1108/EBR-10-2013-0128.

Hajli, N, 2018. Ethical Environment in the Online Communities by Information Credibility: A Social Media Perspective. Journal of Business Ethics, Vol. 149, No. 4, pp 799-810. doi: 10.1007/s10551-016-3036-7.

Huang, L.-T. and Kuo, F.-J, 2014. A Study on Travel Information Adoption Intention in the Online Social Community: The Perspectives of Customer Experience and Information Adoption Model. in PACIS 2014 Proceedings, pp 1-13. Available at: http://aisel.aisnet.org/pacis2014/84/. 
Hussain, S. et al, 2018. Consumers online information adoption behavior: Motives and antecedents of electronic word of mouth communications. Computers in Human Behavior. Pergamon, Vol. 80, pp 22-32. doi: 10.1016/J.CHB.2017.09.019.

Ito, M. et al, 2008. Living and Learning with New Media: Summary of Findings from the Digital Youth Project. Digital Media. doi: 10.1111/j.1548-1379.2010.01107.x.

Kang, M, 2010. Measuring Social Media Credibility: A Study on a Measure of Blog Credibility. Institute for Public Relations, pp 59-68. doi: 10.1136/bmj.g5133.

Ko, D. et al, 2005. Antecedents of Knowledge Transfer in enterprise to clients consultants System Implementations. MIS Quarterly, Vol. 29, No. 1, pp 59-85.

KSEI, 2018. 21 Tahun KSEI: Inovasi Untuk Kenyamanan Transaksi di Pasar Modal. Jakarta. Available at: http://www.ksei.co.id/files/uploads/press_releases/press_file/idid/156_berita_pers_21_tahun_ksei_inovasi_untuk_kenyamanan_transaksi_di_pasar_modal_20190111170001.pdf.

Li, R. and Suh, A, 2015. Factors Influencing Information credibility on Social Media Platforms: Evidence from Facebook Pages. in Procedia Computer Science, pp 314-328. doi: 10.1016/j.procs.2015.12.146.

Madli, F. et al, 2018. Identifying the Factors Influencing Information Usefulness and Information Adoption in Promoting Organ Donation through Social Media. Journal of Media and Information Warfare. Available at: https://jmiw.uitm.edu.my/images/Journal/C3V112.pdf (Accessed: 3 April 2019).

McKnight, D. H. and Kacmar, C. J, 2007. Factors and effects of information credibility, in, p. 423. doi: $10.1145 / 1282100.1282180$.

OECD, 2018. OECD Economic Survey of Indonesia 2018. Available at: http://www.oecd.org/eco/surveys/Indonesia-2018OECD-economic-survey-overview.pdf (Accessed: 5 April 2019).

Otoritas Jasa Keuangan, 2016. Survei Nasional Literasi dan Inklusi Keuangan 2016. Jakarta.

Pitta, D. A. and Fowler, D, 2005. Internet community forums: An untapped resource for consumer marketers. Journal of Consumer Marketing, Vol. 22, No. 5, pp 265-274. doi: 10.1108/07363760510611699.

Sussman, S. W. and Siegal, W. S, 2003. Informational influence in organizations: An integrated approach to knowledge adoption. Information Systems Research, Vol. 14, No. 1, pp 47-65. doi: 10.1287/isre.14.1.47.14767.

Tseng, S.-Y. and Wang, C.-N, 2016. Perceived risk influence on dual-route information adoption processes on travel websites. Journal of Business Research. Elsevier, Vol. 69, No. 6, pp 2289-2296. doi: 10.1016/J.JBUSRES.2015.12.044.

Wathen, C. N. and Burkell, J, 2002. Believe it or not: Factors influencing credibility on the Web. Journal of the American Society for Information Science and Technology, Vol. 53, No. 2, pp 134-144. doi: 10.1002/asi.10016.

We are social, H, 2018. Indonesia Digital Landscape, Special reports digital in 2018: worlds internet users pass the 4 billion mark. Available at: https://wearesocial.com/blog/2018/01/global-digital-report-2018.

Westerman, D., Spence, P. R. and Van Der Heide, B, 2012. A social network as information: The effect of system generated reports of connectedness on credibility on Twitter. Computers in Human Behavior, Vol. 28, No. 1, pp 199-206. doi: 10.1016/j.chb.2011.09.001.

Yan, Q. et al, 2016. E-WOM from e-commerce websites and social media: Which will consumers adopt? Electronic Commerce Research and Applications, Vol. 17, pp 62-73. doi: 10.1016/j.elerap.2016.03.004.

Yang, S. U. and Lim, J. S, 2009. The effects of blog-mediated public relations (BMPR) on relational trust. Journal of Public Relations Research, Vol. 21, No. 3, pp 341-359. doi: 10.1080/10627260802640773. 